\title{
Inkjet-Printed Wideband Antenna on Resin-Coated Paper Substrate for Curved Wireless Devices
}

\author{
Hattan F. Abutarboush, IEEE Member, M. F. Farooqui, A. Shamim, IEEE Senior Member
}

\begin{abstract}
A low-cost, inkjet-printed multiband monopole antenna for conformal wireless applications is presented for the first time. The antenna is implemented on a low cost resin coated paper substrate which can be used for conformal devices. The antenna developed here is composed of four branch lines on the radiator and three $L$-shaped slots on the ground plane that help to generate multiple bands without increasing the size of the antenna. The antenna has a compact size, making it suitable for handheld and wearable wireless devices. Details of the inkjet printing fabrication processes and related issues are presented. The antennas were characterized under flat and bent conditions and the results indicate that the antennas can cover most bands for mobile and wireless applications such as PCS, UMTS, GSM1900 and WLAN.
\end{abstract}

Index Terms-Monopole antenna, Flexible antenna, Wideband antenna, Multiband antenna, Inkjet-printed antennas

\section{INTRODUCTION}

$\mathrm{R}$ ECENT developments in conformal wireless devices have sparked a lot of interest in designing antennas that can be bent and mounted on non-planar objects [1]. Mobile phones or other wireless devices may be developed to be foldable and small in size.

Lower cost is another critical aspect for these types of upcoming wireless devices. Recently, paper has emerged as a material that can reduce the cost to approximately one-tenth of the cost of plastic films or polymers [2]. It has been shown that electronics can be realized on paper substrates through simple processes such as inkjet printing. This could result in further cost savings through roll-to-roll mass manufacturing options [3]. Paper is light weight, environmentally friendly (biodegradable) and comes from a renewable source, making it a very attractive option for such designs. Practical antennas for mobile and wireless applications have typically been designed using flat and rigid substrates such as FR4 [4]-[6]. With such rigid substrates, the antennas cannot be conformal. However, antennas placed on curved substrates, such as, PolyEthylene

Manuscript received July 26, 2014

Hattan F. Abutarboush was formerly with the Computer, Electrical and Mathematical Sciences and Engineering (CEMSE), King Abdullah University of Science and Technology (KAUST), 23955-6900, Saudi Arabia.

A. Shamim and M. Farooqui are with the Computer, Electrical and Mathematical Sciences and Engineering (CEMSE) Division, King Abdullah University of Science and Technology (KAUST), Thuwal 23955-6900, Saudi Arabia.

Email: Hattan.Abutarboush@ieee.org

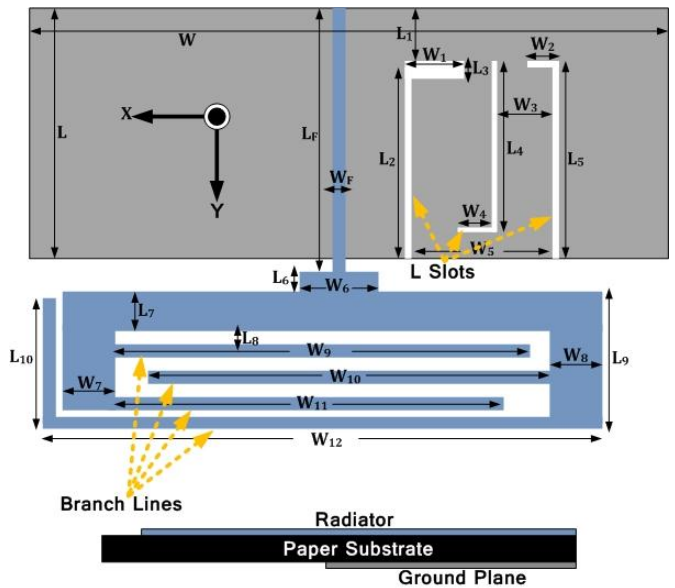

Fig. 1 Layout of the proposed antenna

Terephtalate (PET) [7], Kapton [8], PolyEthylene Naphthalate (PEN) [9], and Liquid Crystal Polymer (LCP) [10] have also been proposed. But these designs have typically been limited to single-band or dual-band applications. In addition, they use relatively expensive fabrication processes and materials. Other conformal antennas using AGHT-8 and LCP substrates [11][12] were also proposed, but these antennas were not designed for multi-band applications.

A few antenna designs have also been reported for paper substrates [13-19], but the effects of bending the antennas were not discussed. Other designs on paper substrates [20-21], have only briefly discussed flexibility. Paper substrates have not been rigorously investigated as substrates for curved inkjet-printed antennas. Such investigation is particularly important in the development of multiband antennas, as maintaining their performance under bent conditions is quite challenging as compared with simple single band antennas. Here, we investigate the performance of a compact and multiband inkjet-printed antenna on a resin-coated photo paper substrate for curved devices for the first time. A thorough investigation is conducted to study the performance of the antenna when it is flat and bent. Measurements of $S_{11}$, the radiation pattern, the gain and the efficiency of the antenna on the paper substrate are presented and discussed in detail.

\section{ANTENNA DESIGN}

The design of the proposed antenna is shown in Fig.1. The antenna consists of a $50-\Omega$ microstrip fed monopole with four branch lines and a ground plane with three L slots. The branch lines and the slots have been used to create multiple frequency 
TABLE1: KEY DIMENSIONS OF THE PROPOSED ANTENNA IN MM

\begin{tabular}{|c|c|c|c|c|c|c|c|c|}
\hline $\mathrm{L}$ & $\mathrm{L}_{1}$ & $\mathrm{~L}_{2}$ & $\mathrm{~L}_{3}$ & $\mathrm{~L}_{4}$ & $\mathrm{~L}_{5}$ & $\mathrm{~L}_{6}$ & $\mathrm{~L}_{7}$ & $\mathrm{~L}_{8}$ \\
\hline 22.37 & 6 & 16 & 2.2 & 13.25 & 16 & 1.42 & 2.37 & 1 \\
\hline $\mathrm{L}_{9}$ & $\mathrm{~L}_{10}$ & $\mathrm{~L}_{\mathrm{F}}$ & $\mathrm{W}$ & $\mathrm{W}_{1}$ & $\mathrm{~W}_{2}$ & $\mathrm{~W}_{3}$ & $\mathrm{~W}_{4}$ & $\mathrm{~W}_{5}$ \\
\hline 9.5 & 9.5 & 23.5 & 40 & 4.1 & 2.1 & 2.5 & 3 & 7.5 \\
\hline $\mathrm{W}_{6}$ & $\mathrm{~W}_{7}$ & $\mathrm{~W}_{8}$ & $\mathrm{~W}_{9}$ & $\mathrm{~W}_{10}$ & $\mathrm{~W}_{11}$ & $\mathrm{~W}_{12}$ & $\mathrm{~W}_{13}$ & $\mathrm{~W}_{F}$ \\
\hline 1.8 & 1.8 & 3.5 & 19 & 28 & 28 & 37.4 & 2.9 & 1 \\
\hline
\end{tabular}

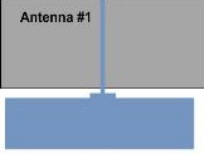

(a)

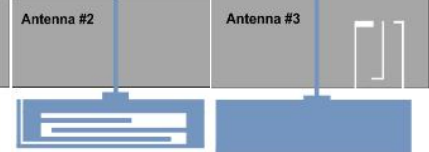

(b)

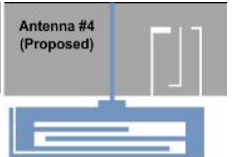

(d)
Fig. 2: Layouts of design steps for the proposed antenna: (a) monopole without any slots, (b) branch lines on top radiator, (c) three L slots on ground plane, and (d) branch lines and three slots on same antenna (proposed).

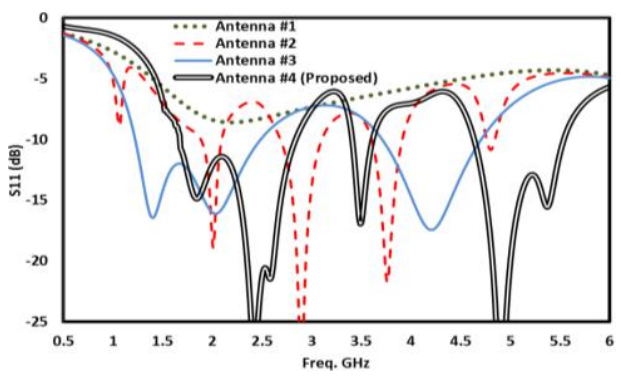

Fig. $3 \mathrm{~S}_{11}$ of the antenna in different steps of Fig. 5 .

bands, as will be described later in this section. The antenna is designed using the high frequency simulation software (HFSS) and has an overall area of $35 \times 40 \mathrm{~mm}^{2}$. The main dimensions of the antenna are listed in Table I. In order to describe the design process, we use four antennas, denoted as antennas \#1, $\# 2$, \#3 and \#4, as shown in Fig. 2. These antennas were designed with photo paper as the substrate. The simulated $S_{11}$ of these antennas are shown in Fig. 3. Antenna \#1 is a simple monopole antenna with a microstrip feed, as shown in Fig. 2(a). It has a single band at approximately $2.1 \mathrm{GHz}$ with an $\mathrm{S}_{11}$ of $-8 \mathrm{~dB}$, as shown in Fig. 3. In Antenna \#2, the four branch lines are added on the radiator (Fig. 2(b)), which create three frequency bands (for $\mathrm{S}_{11}<-10 \mathrm{~dB}$ ) at around 2,3 and $3.9 \mathrm{GHz}$, as shown in Fig. 3. Antenna \#3 is similar to Antenna \#1, but with three L slots etched on the ground plane, as shown in Fig. 2(c). Figure 3 shows that the three L slots create three resonances at $1.4,2$ and $4.3 \mathrm{GHz}$, resulting in a wide frequency band from 1.2 to $2.45 \mathrm{GHz}$ and a narrow band at 4.3 $\mathrm{GHz}$. Antenna \#4 is the proposed antenna which combines both the four branches on the radiator and the three slots on the ground plane, as shown in Fig. 2(d). Figure 3 shows that the frequency bands created by the branch lines and the L slots have been joined together, which allows the antenna to cover multiple bands at $1.71-3.03 \mathrm{GHz}, 3.37-3.66 \mathrm{GHz}$, and 4.51$5.5 \mathrm{GHz}$, without the need to increase the size of the radiator. The multiband behaviour of the antenna can also be understood using current distributions shown in Figs. 4(a)-(e) where current paths for different bands can be identified. The simulated resonant frequencies of $1.95,2.4,3.5,5$ and 5.2 $\mathrm{GHz}$ are used for the study. Fig. 4(a) shows that, at $1.95 \mathrm{GHz}$, a current is concentrated along the edges of the left $\mathrm{L}$ slot on

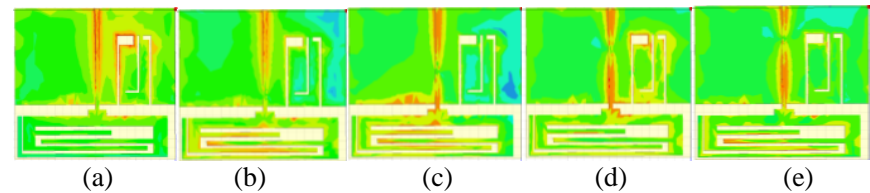

Fig.4 Current distributions at (a) 1.95, (b) 2.4, (c) 3.5, (d) 5, and (e) $5.2 \mathrm{GHz}$.

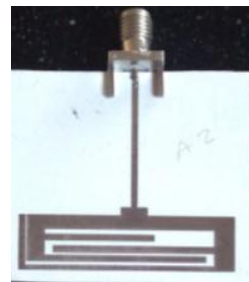

(a)

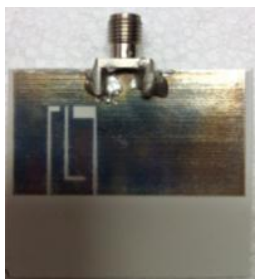

(b)

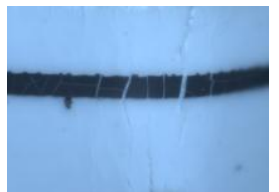

(c)
Fig. 5 Prototype of proposed antenna (a) top layer, (b) bottom layer and (c) cracked ink when bending the antenna.

the ground plane. At $2.4 \mathrm{GHz}$ the current concentrates more on the middle branch lines on the radiator as shown in Fig. 4(b). At $3.5 \mathrm{GHz}$ the current is concentrated more at the edge of the ground plane as shown in Fig. 4(c). At the higher frequencies of 5 and $5.2 \mathrm{GHz}$, Figs. 4(d) - (e) show that the currents concentrate more at the edges of the left L-slot and on the middle branch line on the radiator.

\section{FABRICATION}

\section{A. Inkjet Printing of Antenna}

The photo paper (from Kodak) has been a favourite choice for inkjet printed antennas [14-19]. It has a thickness of $0.22 \mathrm{~mm}$, a dielectric constant of 3.2 and a loss tangent of 0.05 [14]. The reason for its suitability to inkjet printed electronics is that it has a polymer (resin) coating which prevents the ink to get absorbed in the porous paper structure. The antenna shown in Fig. 1 and the dimensions listed in Table I are used to print the antenna on the photo paper using a Dimatix DMP-2831 materials printer, as shown in Fig. 5 (a)-(b). A silver nanoparticle based ink from Sigma-Aldrich has been used. In the printing process, the antenna and the ground plane of the antenna are printed on two sheets of photo papers, each having a thickness of $0.22 \mathrm{~mm}$. Using two sheets help to get a reasonable thickness $(0.44 \mathrm{~mm})$ for the microstrip feedline. Alignment marks have been printed on the photo papers so that the two photo papers can be glued together with correct alignment to form a single antenna substrate. The conductivity of the silver nanoparticle ink printed on the photo paper depends on the number of printed layers. It increases with the number of printed layers; however, it is found that there is no significant increase in conductivity after printing more than six layers. The conductivity value of the ink is around $1 \mathrm{e} 7 \mathrm{~S} / \mathrm{m}$. Therefore, in the final fabrication, six printed layers have been used. The complete assembly is then put inside an oven for sintering the nanoparticle ink at about $140{ }^{\circ} \mathrm{C}$ for around 2 hours. Sintering is required to heat the metal nanoparticles beyond their melting temperature to form continuous metal tracks. In an attempt to bend the antenna after the sintering process resulted in cracks in the printed structure as shown in Fig. 5(c). Further investigation of this matter revealed that sintering of the resin coating layer makes 


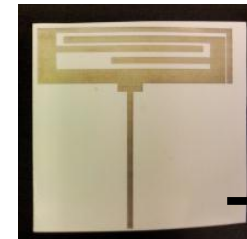

(a)

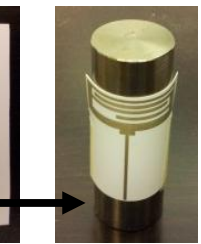

(b)

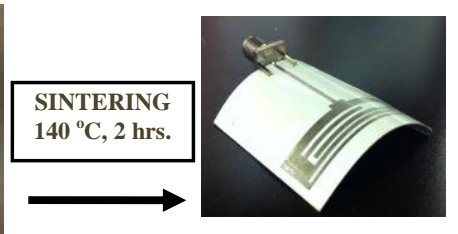

(c)
Fig. 6 Fabrication process for the curved prototype: (a) flat antenna, (b) antenna mounted on a cylindrical surface and sintered and (c) the fabricated antenna with a connector added after removal of the cylinder.

it stiff and this results in cracking of the antenna if bent. A way around this was found by sintering the antenna after bending it to the required curvature (see Fig. 6). By doing so, no cracking was observed. As can be seen in Fig. 6 (c), the bent antenna retains its curved shape and can be used in curved devices. Therefore, the process shown in Fig. 6 is suitable for conformal antennas which are required to be mounted on poles or round structures of known radius. Using this method, we have fabricated two antennas with the bent radii of 27.5 and a $37.5 \mathrm{~mm}$ which are arbitrarily chosen.

\section{RESULTS}

\section{A. Impedance Bandwidth for $S_{11}<-10 \mathrm{~dB}$}

The simulated and measured $S_{11}$ of the flat antenna (shown in Fig. 5) are plotted in Fig .7. In general, the two curves follow the same trend, indicating good agreement between simulations and measurements. However, small differences of about $(100-300 \mathrm{MHz})$ are seen in the lowest and highest frequency bands, which can be due to the misalignment of the top and bottom layers of the antenna and printing tolerance. In simulations, a low and wide frequency band $(1680-2840$ $\mathrm{MHz}$ and $51.3 \%$ bandwidth) is formed by the lowest three resonances at 1.95, 2.4 and $2.7 \mathrm{GHz}$, a narrow band at 3.5 $\mathrm{GHz}(3400-3640 \mathrm{MHz}$ and $6.81 \%$ bandwidth) is formed by a single resonance, and a wide frequency band (4640 - 5600 MHz with $18.75 \%$ bandwidth) is formed by two resonances at4.7 and 5.2 GHz. These frequency bands can cover the Personal Communication System (PCS), Digital Communication Systems (DCS), Global System for Mobile Communications (GSM 1800) and (GSM 1900 ), Universal Mobile Telecommunications System (UMTS), WiBro, Wireless Local Area Networks (2.4 and 5.2 GHz WLAN), SDMB, Worldwide Interoperability for Microwave Access (WiMAX) band II , LTE2300, LTE2500 and IEEE 802.11a WLAN band [4]-[15]. The $S_{11}$ of the two curved antennas with bent radii of 27.5 and a $37.5 \mathrm{~mm}$ shown in Fig. 6, have been plotted in Fig. 8. The measured $S_{11}$ for the flat antenna is also shown in the same figure for the sake of comparison. Table II lists the frequency bands of the three antennas. Figure 8 shows that the bandwidth of the antenna is affected slightly by bending. The lower band of the flat antenna is about 55.6\%. With a bent radius of $27.5 \mathrm{~mm}$, the bandwidth increases to $62.6 \%$. With the large bent radius of $37.5 \mathrm{~mm}$, the wide frequency band is split into two bands, from $1.68-2.16 \mathrm{GHz}$ and from $2.4-3.01 \mathrm{GHz}$. These bandwidths are wide enough (25\% for the first band and $22.22 \%$ for the second band) to support common mobile standards such as PCS, DCS, UMTS,

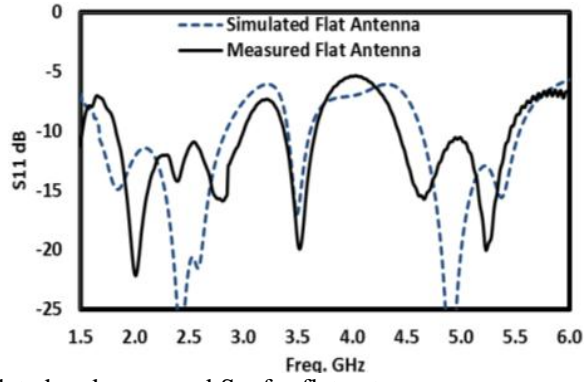

Fig. 7: Simulated and measured $\mathrm{S}_{11}$ for flat antenna

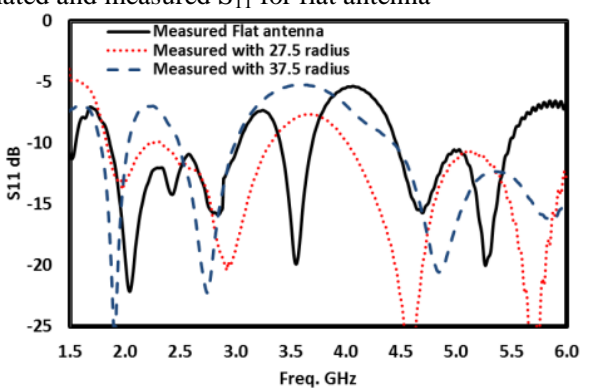

Fig.8: Measured $\mathrm{S}_{11}$ results for flat and curved antennas

TABLE II: B.W OF FLAT AND CURVED ANTENNAS FOR S11<-10 DB)

\begin{tabular}{|c|c|c|c|}
\hline $\begin{array}{c}\text { Antenna } \\
\text { Type }\end{array}$ & $\begin{array}{c}\text { Low frequency } \\
\text { bands }\end{array}$ & $\begin{array}{c}\text { Middle } \\
\text { frequency band }\end{array}$ & $\begin{array}{c}\text { High frequency } \\
\text { bands }\end{array}$ \\
\hline Flat & $\begin{array}{c}\text { Wideband } \\
1.71-3.03 \mathrm{GHz}\end{array}$ & $\begin{array}{c}\text { Narrow band } \\
3.37-3.66 \mathrm{GHz}\end{array}$ & $\begin{array}{c}\text { Wideband } \\
4.51-5.5 \mathrm{GHz}\end{array}$ \\
\hline $\begin{array}{c}\text { Curved : } 27.5 \\
\text { radius }\end{array}$ & $\begin{array}{c}\text { Wideband } \\
1.70-3.25 \mathrm{GHz}\end{array}$ & -- & $\begin{array}{c}\text { Wideband } \\
4.05-6 \mathrm{GHz}\end{array}$ \\
\hline $\begin{array}{c}\text { Curved: } 37.5 \\
\text { radius }\end{array}$ & $\begin{array}{c}\text { Dual-band } \\
(1.68-2.16 \mathrm{GHz}) \\
(2.4-3.01 \mathrm{GHz})\end{array}$ & -- & $\begin{array}{c}\text { Wideband } \\
4.39-6.1 \mathrm{GHz}\end{array}$ \\
\hline
\end{tabular}

GSM1800 and 1900, WiMAX-I and WLAN/Bluetooth. In the middle frequency band, a single narrow band is generated at $3.5 \mathrm{GHz}$ from the flat antenna as shown in Fig. 8. However, when the antenna is curved, this band is lost and becomes unmatched. A possible explanation for this could be due to the concentration of the current at the edge of the ground plane, which affected the matching of the $3.5 \mathrm{GHz}$ band during the bending. Although the $3.5 \mathrm{GHz}$ for WiMAX application is lost and become unmatched, other WiMAX bands such as 2.5 and $5.8 \mathrm{GHz}$ are still covered and can be used. Finally, in the high frequency bands, the bandwidths of the curved antennas with 27.5 and $37.5 \mathrm{~mm}$ bend radii are greatly improved as compared to the flat antenna. In this section, it is observed that the flat antenna has a wide bandwidth, but when the antenna is curved, the lower bands are affected by the bending and the bandwidth in the higher bands is increased. This is due to the curved structure that affects the electrical length of antennas' resonance length.

\section{B. Radiation Pattern, Gain and Efficiency}

The radiation patterns of the flat and curved prototype antennas have been measured using antenna measurement equipment, StarLab, from Satimo. The measured radiation patterns for the co-polarizations in the X-Z (E-Plane) and X-Y (H-Plane) at the frequencies of 1.9, 2.4, and $5 \mathrm{GHz}$ are shown in Fig. 9 (a)-(c), respectively. The results show a monopoleshaped radiation pattern in the E-plane and an omnidirectional pattern in the H-plane. There is good agreement between the 

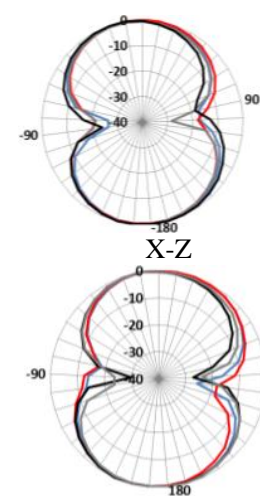

(a)

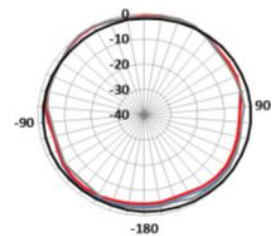

(a) $\mathrm{X}-\mathrm{Y}$
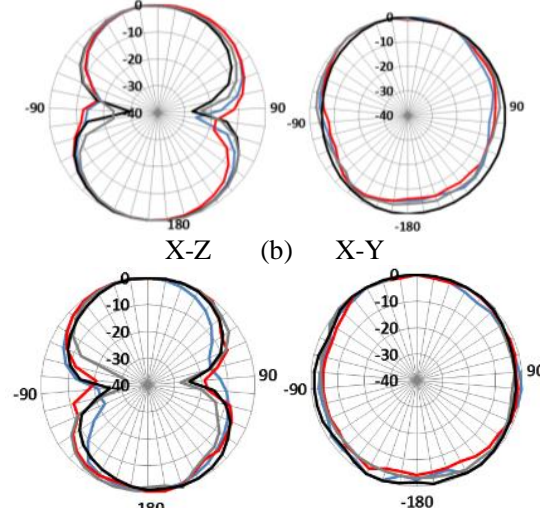

(b) X-Y

$\mathrm{X}-\mathrm{Z}$

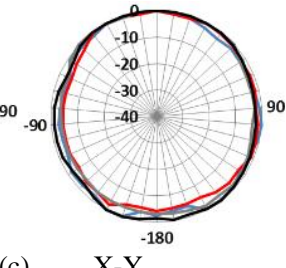

(c) X-Y

- Simulated Co-Pol (Flat Antenna)

-Measured Co-Pol (Flat Antenna)

- Measured Co-Pol (Curved Antenna with 27.5 Radius)

-Measured Co-Pol (Curved Antenna with 37.5 Radius)

Fig. 9: Simulated and measured co-polarizations in $\mathrm{X}-\mathrm{Z}$ and $\mathrm{X}-\mathrm{Y}$ directions at (a) $1.9 \mathrm{GHz}$, (b) $2.4 \mathrm{GHz}$ and (c) $5 \mathrm{GHz}$ for flat and curved antennas.

simulated and measured patterns for the flat antenna. The measured patterns for the curved antennas are quite similar to the flat case. This indicates that bending the antenna does not affect the radiation patterns by much. Low levels $(<-15 \mathrm{~dB})$ of cross polarization are observed at 1.9 and $2.4 \mathrm{GHz}$ and slightly higher levels (>-10 dB) are observed at $5 \mathrm{GHz}$. For clarity, the measured cross polarization is not shown in Fig. 9 (a)-(c). Figure 10 shows that the measured peak gains of the flat and curved antennas follow the same trend. The measured efficiency of the flat antenna ranges between $45 \%$ and $58 \%$, but drops by approximately $8 \%$ when the antenna is curved.

\section{CONCLUSIONS}

A study has been carried out to assess the performance of an inkjet-printed antenna on a resin-coated photo paper substrate. It has been found that the resign-coated paper is suitable for curved or conformal antennas due to the hardening of the resin coating layer during the sintering process. Measured results have shown that the antenna under the flat and bent conditions can cover most of the bands for mobile and wireless applications. When the antenna is bent, the bandwidth is increased but the gain is dropped. Bending the antenna does not change the radiation patterns much.

\section{REFERENCES}

[1] Li Yang, R. Zhang, D. Staiculescu, C. P. Wong, M. M. Tentzeris, "A Novel Conformal RFID-Enabled Module Utilizing Inkjet-Printed Antennas and Carbon Nanotubes for Gas-Detection Applications," IEEE Antennas and Wireless Propagation Letters, vol.8 ,pp.653,656, 2009.

[2] A. Steckl, "Circuits on cellulose," IEEE Spectrum, vol.50, no.2, pp.48-61, Feb. 2013.

[3] S. Koskinen, L. Pykari, M. Mantysalo, "Electrical Performance Characterization of an Inkjet-Printed Flexible Circuit in a Mobile Application," IEEE Transactions on Components, Packaging and Manufacturing Technology, vol.3, no.9, pp.1604,1610, Sept. 2013.

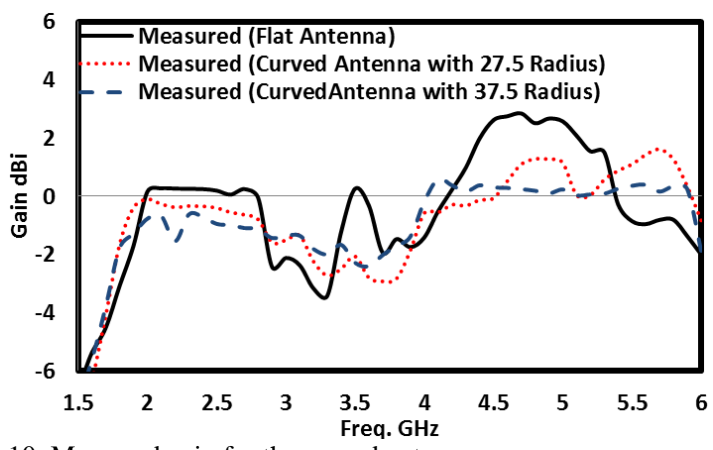

Fig. 10: Measured gain for the curved antenna

[4] H. F. Abutarboush, H. Nasif, R. Nilavalan, and S. W. Cheung, "Multiband and Wideband Monopole Antenna for GSM900 and Other Wireless Applications" IEEE Antennas and Wireless Propagation Letters, May 2012.

[5] C. Chiu, C. Chan, K. Luk, "Study of a small wide-band patch antenna with double shorting walls," IEEE Antennas and Wireless Propagation Letters, vol.3, no.1, pp.230-231, Dec. 2004

[6] H. F. Abutarboush, R. Nilavalan, T. Peter and S. Cheung, "Multiband Inverted-F Antenna with Independent Bands for Small and Slim Cellular Mobile Handsets," IEEE Transaction on Antennas and Propagation, Vol. 59, No. 7, 2011.

[7] D. Betancourt, J. Castan, "Printed Antenna on Flexible Low-Cost PET Substrate for UHF Applications," Progress In Electromagnetics Research C, Vol. 38, 129-140, 2013.

[8] H. R. Khaleel, H. M. Al-Rizzo, D. G. Rucker, "Compact Polyimide-Based Antennas for Flexible Displays," Journal of Display Technology, vol.8, no.2, pp.91-97, Feb. 2012.

[9] C. Durgun, C. Balanis, C. Birtcher, D. Allee, "Design, Simulation, Fabrication and Testing of Flexible Bow-Tie Antennas," IEEE Transactions on Antennas and Propagation, vol.59, no.12, pp.4425-4435, Dec. 2011.

[10] L. Marnat, A. Shamim, "Liquid Crystal Polymer (LCP) based antenna for flexible system on package (SoP) applications," 15th International Symposium on Antenna Technology and Applied Electromagnetics (ANTEM), pp.1-4, 25-28 June 2012.

[11] S. Nikolaou, M. M. Tentzeris, J. Papapolymerou,"Study of a conformal UWB Elliptical Monopole Antenna on Flexible Organic Substrate Mounted on Cylindrical Surfaces", The 18th Annual IEEE International Symposium on Personal, Indoor and Mobile Radio Communications (PIMRC'07), 2007.

[12] T. Peter and R. Nilavalan, "Study on the performance deterioration of flexible UWB antennas," Antennas and Propagation Conference Loughborough (LAPC'09), pp. 669-672, 2009.

[13] S. Kim, R. Yu-Jiun, L. Hoseon, A. Rida, S. Nikolaou, M. Tentzeris, "Monopole Antenna With Inkjet-Printed EBG Array on Paper Substrate for Wearable Applications," IEEE Antennas and Wireless Propagation Letters, vol.11, no., pp.663,666, 2012.

[14] B. S. Cook, A. Shamim, "Inkjet Printing of Novel Wideband and High Gain Antennas on Low-Cost Paper Substrate," IEEE Transactions on Antennas and Propagation, , vol.60, no.9, pp.4148-4156, Sept. 2012.

[15] H. F. Abutarboush, A. Shamim, "Paper-Based Inkjet-Printed Tri-Band USlot Monopole Antenna for Wireless Applications," IEEE Antennas and Wireless Propagation Letters, vol.11, pp.1234-1237, 2012.

[16] H. F. Abutarboush, A. Shamim, "Conformal and green electronics: A wideband inkjet printed antenna on paper substrate," 7th European Conference on Antennas and Propagation, pp.3099-3102, April 2013.

[17] H. F. Abutarboush,A. Shamim,"Wide frequency independently controlled dual-band inkjet-printed antenna," IET Microwaves, Antennas and Propagation, vol.8, no.1, pp.52-56, January 2014.

[18] B. Cook, A. Shamim, "An inkjet-printed UWB antenna on paper substrate utilizing a novel fractal matching network," IEEE Antennas and Propagation Society International Symposium (APSURSI), 2012, pp.1,2, 8-14 July 2012

[19] G. Shaker, Safavi-Naeini, Safieddin; N. Sangary, M. M. Tentzeris, "Inkjet Printing of Ultrawideband (UWB) Antennas on Paper-Based Substrates," IEEE Antennas and Wireless Propagation Letters, vol.10, pp.111,114, 2011

[20] L. Yang, R. Zhang, D. Staiculescu, C. Wong, and M. Tentzeris, "A novel conformal RFID-enabled module utilizing inkjet-printed antennas and carbon nanotubes for gas-detection applications," IEEE Antennas Wireless Propagation Letter, vol. 8, pp. 653-656, 2009.

[21] D. E. Anagnostou, A. A. Gheethan, A. K. Amert, and K. W. Whites, "A direct-write printed antenna on paper-based organic substrate for flexible displays and WLAN applications," J. Display Technol., vol. 6, no. 11, pp. 558-564, Nov. 2010 